\title{
Feminización de la vejez \\ y Estado del Bienestar en España
}

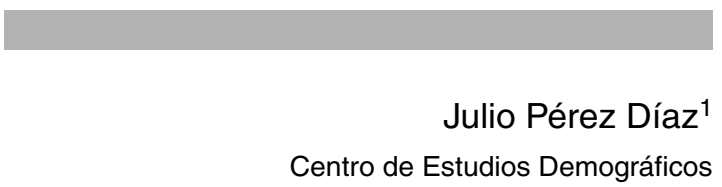

Centro de Estudios Demográficos

RESUMEN

Se va a sostener aquí que la transformación de la dinámica poblacional conocida como «transición demográfica» es un importante motor de cambio no sólo en la distribución de la población entre las diferentes edades, sino también en la de los roles tradicionalmente asignados a cada sexo.

Se trata de cambios estrechamente relacionados. El creciente peso de las personas de edad madura y avanzada, y la generalización de la supervivencia hasta dichas edades, abren nuevas posibilidades de organización social y familiar, y nuevos «diseños» de ciclo vital individual. Sostendré que la distribución de roles productivos y reproductivos está dejando de tener al sexo como eje, para articularse en torno a la edad. Es bien sabido que las edades jóvenes y adultas se orientan cada vez más hacia comportamientos hasta ahora considerados «masculinos», y se sugiere que las edades maduras y avanzadas podrían estar experimentando una preponderancia inversa de aquellos otros hasta ahora considerados «femeninos». Es esa «feminización de la vejez» el fenómeno que se pretende demostrar a continuación, argumentando, además, las ventajas y riesgos sociales que implica.

Palabras clave: Tercera Edad, Mujer, Estado del Bienestar, Demografía, Género, Envejecimiento Demográfico, Familia, Relaciones Intergeneracionales, Vejez.

1 Este artículo desarrolla algunas ideas ya enunciadas en «Las mujeres ancianas, la auténtica vejez de la España actual» (1995), ampliadas en 1999 por la colaboración con Anna Cabré en El advenimiento de la madurez de masas (en prensa). El primer fruto fue «La feminización de la vejez» (2000), presentado en el International Seminar on Gender and Demography de la ISA (Madrid, 1999) y antecedente inmediato del trabajo que aquí se presenta. 


\section{LA EDAD Y EL CAMBIO EN LOS ROLES DE GÉNERO}

Para la sociología funcionalista de los años cuarenta, los roles ligados al sexo eran altamente inertes y rígidamente determinados. No en vano, el «rol» constituía, junto al estatus, el marco estructural de la acción (Parsons, Shils et al., 1951). La edad, el otro factor clásico de asignación de roles y de estatus, era entendida por Sorokin (1941) o el propio Parsons (1942) como criterio universal de identificación social y de distribución de recursos, con formas específicas en cada civilización, también difícilmente maleables.

No es de extrañar el progresivo abandono o reelaboración de dicho marco teórico: contra sus premisas, género y edad vienen cambiando su significación a un ritmo inusitado. El género, además, ha tenido en el feminismo un importante agente de cambio, que muy pronto buscó otros paradigmas conceptuales que incluyesen el activismo político como factor fundamental de transformación.

El que más aceptación obtiene últimamente es el de la economía política. En él, los Estados contemporáneos son finalmente reconocidos como poderoso agente de estructuración social, capaz de modificar las posiciones y los recursos que el mercado, por sí mismo, asignaría a los individuos. Los cambios de género se entienden paralelos al desarrollo del Estado del Bienestar, y el feminismo se siente partícipe directo al haber impregnado de igualitarismo las políticas públicas. Incluso el descenso de la fecundidad y, en general, de la dedicación femenina a las tareas reproductivas parecen resultar de tales políticas en materias como la planificación familiar, el aborto, el divorcio, la educación o la legislación laboral. Quienes deploran sus costos o persiguen la salvaguarda de valores supuestamente perdidos, como los familiares, han asumido el mismo marco explicativo.

Con cierto retraso, y sin un activismo impulsor tan definido, el rapidísimo cambio en la significación social de las edades acaba explicándose también en dicho marco (Quadagno y Reid, 1997). No en vano, los sistemas educativos, las leyes penales, la plenitud de derechos políticos, los límites de la vida activa o la posibilidad de percibir pensiones de vejez son ejemplos claros de asignación de roles y de recursos, por parte del Estado, en función de la edad. A su intervención atribuye Samuel Preston (1985) ${ }^{2}$ el creciente bienestar de la vejez, y lo mismo hacen quienes, como él, vienen denunciando los «excesos protectores» del Estado y la supuesta injusticia intergeneracional que provocan (Longman, 1987; Díaz Casanova, 1989).

2 Artículo histórico donde, por primera vez, se demuestra empíricamente que el envejecimiento demográfico no produce el deterioro previsto en el bienestar de los mayores. 
En mi opinión, se está sobrevalorando la capacidad del Estado para modificar los roles de género y edad. La pujanza de la economía política como marco teórico coincide con el intenso debate generado por el neoliberalismo desde los años ochenta. En ese debato, tanto los ensalzadores de lo mucho conseguido como los críticos del excesivo papel del Estado han hecho de la investigación social un terreno en que dirimir sus propias teorías, contagiándola de «estatocentrismo».

Añádase que, con ello, la sociología de género y la de las edades se distancian aún más que en el funcionalismo de los años cuarenta. La igualación femenina es vista como un éxito de sus protagonistas, pero no así las mejoras de la vejez. Las edades no son actores sociales (Requena, 1992) y la generación de nacimiento, ésta sí, característica temporal permanente de los individuos, no ha sido todavía introducida como elemento relevante en el marco teórico de la economía política. Se habla de «relaciones intergeneracionales» para referirse a los equilibrios entre cotizantes y pensionistas, o para analizar las interrelaciones entre personas vinculadas por filiación, pero en ambos casos sigue siendo la edad y no la generación la que constituye realmente el criterio de análisis. Su auténtica integración teórica requeriría una investigación más compleja que la habitual, viendo en cada edad el resultado del recorrido vital en todas las edades anteriores. Mejoraría nuestra comprensión de los efectos que tiene la interrelación entre Estado, mercado y familia sobre las relaciones de género y la significación social de cada edad y, sobre todo, de las edades avanzadas.

Ese es mi propósito aquí: analizar los espectaculares cambios experimentados recientemente por la vejez en España, conservando el marco de la economía política, pero integrando las trayectorias generacionales en el análisis. Como ya he expuesto en otro lugar (Pérez Díaz, 2001b), las mejoras de las últimas dos o tres décadas deben menos a las políticas públicas que al relevo generacional entre los mayores. Sostendré que el retraso y la rapidez con que culmina la modernización sociodemográfica española hacen convivir actualmente una constelación sumamente heterogénea de generaciones cuyo reparto de funciones no sólo está orientando las transformaciones del lugar social de la vejez, sino también la de los géneros. El ámbito nuclear de ese cambio es, claro está, la familia (Moreno, 2001), y los cambios de género no sólo se dan en las mujeres jóvenes. Los hombres también se feminizan, pero en la vejez.

\section{EL CAMBIO DE LA VEJEZ EN ESPAÑA}

Según el tópico, es la juventud la que impulsa las revoluciones e irrumpe generación tras generación inyectando creatividad, energías renovadas y sed de cambio. Son muchos 
quienes, como Ortega y Gasset, han teorizado sobre dicha base; los mayores son supuestamente estáticos, representan la tradición y el pasado, aferrados a lo ya conseguido y recelosos de las novedades. Pero son esas personas las que hoy encabezan una reestructuración sin precedentes del entramado social que nos afecta a todos.

Buena parte de su carácter innovador es fruto de las tardías pero rapidísimas transformaciones demográficas experimentadas por España durante el siglo xx, especialmente las relativas a la mortalidad. Al margen de los deseos, aspiraciones, experiencias o capacidades de quienes nacieron desde principios de ese siglo, la democratización de la supervivencia hasta edades muy avanzadas les convierte en auténticos pioneros de un geografía vital antes desierta e inexplorada. Sin antecedentes, sin los modelos de conducta que proporcionan quienes transitan antes un camino, son sus propias adaptaciones y «ensayos» en la colonización masiva de la vejez los que allanan el terreno a las generaciones posteriores.

Y es en la familia donde dicho carácter de avanzadilla resulta más evidente. Los nacidos a principios de siglo cumplieron los cincuenta años siendo huérfanos de padre y de madre en su gran mayoría. En cambio, más del $60 \%$ de los nacidos en los años treinta ha cumplido dicha edad teniendo algún progenitor vivo. En las generaciones nacidas en la segunda mitad de siglo, que llegan a la madurez a partir de ahora, la supervivencia de los progenitores es ya espectacularmente mayoritaria. En muy poco tiempo lo raro se ha convertido en normal: gozar de la existencia de los propios progenitores mientras se atraviesan las edades adultas e incluso la primera vejez ${ }^{3}$ (Pérez Díaz, 2001a).

Se extiende también la coexistencia de cuatro generaciones ligadas por filiación directa, y el cambio de perspectiva vital que ello produce es notable. Para los niños, que conocen a sus bisabuelos; para los adultos, que traen hijos al mundo teniendo aún vivos a sus propios abuelos; para quienes tienen nietos y, pese a todo, se sienten jóvenes porque aún no son la generación más antigua de su línea familiar. Son situaciones rarísimas en la historia humana que en España se han vuelto frecuentes en las últimas décadas, y muy pronto resultarán mayoritarias. Las generaciones femeninas nacidas en 1970-1974 tienen un 45\% de probabilidades de que su primer hijo nazca teniendo bisabuela/o (CED, 2000), y tales probabilidades no van a hacer más que aumentar en las generaciones posteriores.

El impacto de tales novedades sobre los comportamientos asociados a la edad puede tardar en ser investigado y comprendido, pero es evidente. No lo es, en cambio, en los com-

3 Estos y otros datos generacionales se han obtenido reelaborando los microdatos de la Encuesta Sociodemográfica (INE, 1991), una fuente sin precedentes en la historia estadística española por su carácter retrospectivo, por la riqueza de su cuestionario y por su inusitado volumen muestral. 
portamientos asociados al sexo. Pero es en la familia donde con mayor intensidad y frecuencia se relacionan personas de diferente sexo y edad, relaciones que son el principal catalizador de la asignación diferenciada de funciones. No es creíble que la asignación ligada al sexo haya permanecido inmune a transformaciones demográficas que afectan a la reproducción, uno de los núcleos esenciales de las estrategias familiares (Garrido Medina, 1996).

Lo femenino se definía hasta hace muy poco fundamentalmente en torno a la reproducción biológica y social en el seno de la familia, mientras el papel exclusivamente productivo y "externo» al hogar definía la masculinidad. Esa manera concreta de distribuir los roles guarda una estrecha relación con la dinámica demográfica históricamente imperante en las poblaciones humanas. Si se quiere comprender la manera en que la «revolución demográfica» iniciada en los siglos XVIII y XIX afecta a las tradicionales funciones de género, conviene tener presentes las condiciones en que antes se movían la vida, la muerte, el trabajo y la reproducción de las personas.

\section{FAMILIA, GÉNERO Y EDAD, Y SU RELACIÓN CON LA TRANSICIÓN DEMOGRÁFICA}

La precariedad de la vida ha sido siempre la principal limitación humana para adoptar estrategias distintas a las socialmente consolidadas. Mortalidades superiores al $200 \%$ durante el primer año de vida eran corrientes en el pasado (en España hasta el final del siglo XIX), y más de la mitad de los nacidos moría antes de cumplir los diez ${ }^{4}$. Guerras, hambre y epidemias se encargaban recurrentemente de frustrar el resto de «sus días» a la otra mitad (Livi Bacci, 1990).

Frente a los tópicos familiaristas sobre el pasado, los supervivientes hasta edades fecundas eran escasos, y no todos podían tener hijos. En las economías agrarias la constitución de una familia propia era una empresa difícil y muy costosa, que los hombres sólo podían emprender tardíamente, heredando tierras o acumulando los recursos necesarios tras muchos años de trabajo. Las mujeres aún lo tenían más difícil. Se casaban más jóvenes, pero los varones con que se emparejaban pertenecían a generaciones anteriores, menguadas por la mortalidad y, por lo tanto, insuficientes para atender toda la «demanda» nupcial femenina ${ }^{5}$.

\footnotetext{
4 En Gómez Redondo (1992) se describe de forma completa, a partir de estadísticas modernas, el descenso de la mortalidad infantil española a lo largo del siglo xx. Ramiro Farinas (1998) y Sanz Gimeno (1999), desde el ámbito de la demografía histórica, tratan los inicios de dicho descenso, en el siglo anterior.

5 Los desequilibrios entre sexos en el mercado matrimonial son un determinante demográfico estructural sumamente rígido para los roles de género (Cabré, 1994). El tradicional carácter «excedentario» de las mujeres no se rompe en España hasta
} 
Los pocos que conseguían tener hijos respondían a cambio con una elevada fecundidad, lo que configura un sistema demográfico sumamente ineficiente dada la gran inversión de esfuerzos y de vidas humanas necesaria, simplemente, para sostener la población. Es difícil imaginar hoy la intensidad del trabajo que comportaba tener familia y la precariedad de la empresa, sometida al alto riesgo de muerte tanto de la pareja como de los propios hijos. Aunque algunas familias fuesen extensas y contasen con la colaboración de otros parientes, muchas sucumbían a los efectos de la temprana e indiscriminada mortalidad. Los «sin familia» (adultos solteros, menores huérfanos, viudos precoces) eran mucho más frecuentes, las madres no podían prestar demasiada atención a los hijos, éstos tenían que ser precozmente «productivos» (Caldwell, 1983) y el papel de los abuelos y abuelas era sumamente escaso, porque pocos sobrevivían para serlo (Segalen, 1995; Hareven, 1994). Sobre todo, era sumamente improbable que los niños llegasen a edades adultas teniendo a sus dos progenitores vivos. En ese marco debía moverse la asignación de papeles según la edad y el sexo.

Con los albores de la transición demográfica la mortalidad, especialmente la infantil, inicia lo que será un drástico descenso, trastornando completamente las condiciones para la reproducción y, por tanto, para los roles de género. De generaciones que perdían la mitad de sus efectivos antes de los diez años hemos pasado a generaciones como las nacidas en los años sesenta en España, cuyos supervivientes seguirán siendo más de la mitad hasta haber sobrepasado los noventa años (Pérez Díaz, 2001a). Este salto cualitativo suele atribuirse, de manera vaga y general, a la industrialización y al desarrollo económico, pero es mucho menos frecuente el reconocimiento del papel mediador de quienes asumían en exclusiva las tareas de reproducción, las madres. Y, sin embargo, ambas cosas están ligadas. Con la industrialización aparece una novedad histórica en las relaciones de género: la posibilidad de que la mayoría de los hombres reciban, siendo muy jóvenes aún, un «salario familiar» que les permite casarse sin la colaboración económica de sus propios padres o sin la dote de su futura mujer, y la posibilidad, además, de que la mayoría de las mujeres pueda contraer matrimonio y dedicarse entonces principalmente a las tareas domésticas y al cuidado de los hijos (Donzelot, 1979).

Este tipo de familia tiene cada vez menos hijos y cada vez más concentrados en el tiempo, pero ni el esfuerzo de provisión económica de los padres ni el esfuerzo reproductivo de las madres disminuyen. Lo que ocurre es todo lo contrario. Por fin a salvo del intolerable riesgo de fallecimiento de uno de sus miembros, la pareja complementaria asume en solitario

las generaciones nacidas en la segunda mitad de los años treinta (con mucho retraso respecto a las pautas europeas), y su consecuencia más visible es que son también las primeras generaciones femeninas con una soltería inferior a la de sus coetáneos masculinos (Pérez Díaz, 2001a). Esta es sólo una más de las innovaciones vitales que protagonizan quienes en la actualidad están cumpliendo 65 años. 
la empresa de tener hijos. El precio es elevar hasta extremos inauditos la intensidad y la duración del «trabajo respectivo». A cambio de tanto esfuerzo, estas parejas «transicionales» ponen sus hijos definitivamente a salvo tanto de la mortalidad temprana como de la obligación de contribuir precozmente a la economía familiar. Hijos que, por primera vez de manera generalizada, pueden cursar estudios prolongados, de más de diez años, y empezar a construir un nuevo tipo de transcurso vital con unos recursos y una esperanza de vida que les hacen radicalmente diferentes a sus propios padres. El cambio inicial produce más cambio.

En lo que atañe al objetivo de este artículo, lo más destacable de este proceso transicional es que no altera sólo la significación de las edades adultas e infantiles; también tiene efectos sobre los familiares de mayor edad. Los cambios del sistema productivo, con el desmantelamiento de una economía preponderantemente agraria, la autosuficiencia de unos jóvenes prontamente asalariados, el abandono del mundo rural y las intensas migraciones hacia las ciudades, rompen los fundamentos del ciclo vital y familiar de las personas con edades maduras y avanzadas, que ya no tienen tiempo para reconvertirse tal como aún pueden hacer sus hijos. En brusco contraste con un pasado no muy lejano, ni sus tierras, ni sus patrimonios, ni sus oficios, experiencias y conocimientos sirven ya de nada a sus descendientes. Se produce así una inversión en los respectivos papeles que no tiene precedentes, por la cual la situación cultural, económica y social de quienes todavía han vivido poco es mejor que la situación de quienes han vivido mucho. El mundo, en esos tiempos, es de los jóvenes.

Es entonces cuando se construye la imagen asistencial y conmiserativa de la vejez todavía hoy vigente. El papel de la vejez desde esta óptica es no tener ningún papel, ninguna función social o familiar (Cumming y Henry, 1961). Antes bien, lo que define a las edades avanzadas es su «discapacidad», que se revela en sus carencias económicas, su escaso o nulo nivel de instrucción, su mala salud, su falta de adaptación y su soledad (la mayor parte son mujeres viudas).

Puesto que la gerontología nace y se desarrolla simultáneamente a tales cambios, termina por asumir ese reparto de funciones entre sexos y edades como el modelo propio de las sociedades industrializadas (Beauvoir, 1983), sin atender al carácter extraordinario y coyuntural de las condiciones en que se basa.

Las nuevas familias, coincidentes con el modelo «nuclear» de los hogares, llegan a ser, en efecto, las preponderantes en las sociedades industrializadas, pero ello no ocurre en España hasta prácticamente las generaciones nacidas entre los años treinta y cincuenta, con mucho retraso respecto al resto de Europa. Son las generaciones fecundas en los años se- 
senta y setenta, y alcanzan edades maduras y avanzadas a partir de finales del siglo XX, es decir, en la actualidad (Pérez Díaz, 2001a). Sus características y las de las generaciones que les siguen subvierten los tópicos anteriores sobre las respectivas edades.

La rapidez con que tales cambios se han producido en España la convierte en un observatorio privilegiado para estudiar las modificaciones en la significación del sexo y la edad favorecidas por la transición. Pero también plantea las particularidades de la coexistencia temporal de perfiles vitales tan heterogéneos en las líneas de filiación y en el conjunto social. Contamos con la presencia en vida de prácticamente todas las generaciones implicadas en ese cambio. En otros países desarrollados el proceso se inició mucho antes y fue más gradual.

\section{LA IGUALDAD EN LAS GENERACIONES RECIENTES}

Los roles de género en las generaciones españolas más recientes evolucionan hacia la igualación. Ha desaparecido la segregación escolar. Por primera vez, las jóvenes españolas alcanzan (y superan) los años de estudios y los niveles académicos de los varones. Las familias ya no usan a las niñas y adolescentes como soporte en los trabajos domésticos, ni las controlan más que a sus hermanos en sus horarios, contactos sociales, relaciones de pareja o hábitos de consumo. Sus tasas de actividad crecen. Mantienen el trabajo en las edades casaderas y al vivir en pareja (Garrido, 1992). Desaparece su hipergamia matrimonial (el emparejamiento con un cónyuge de mayor nivel socioeconómico o cultural había sido la norma histórica). Y, sobre todo, ya no se ven abocadas a las tareas reproductivas como principal ocupación en la vida. Se casan tarde, tienen pocos hijos, deciden la edad a la que los tienen y la supeditan a la consolidación laboral (Alberdi, 1995).

Todas esas novedades se han producido en medio de una gran expectación y han sido profusamente documentadas y analizadas, dados su carácter innovador y las grandes esperanzas de igualdad que han despertado. La gran relevancia social y política otorgada a la fecundidad favorece la existencia de estadísticas abundantes y detalladas sobre los comportamientos femeninos en esta materia. Otro tanto podría decirse respecto a la información generada por el sistema educativo y, aún más, sobre las pautas de actividad laboral, uno de los ámbitos de conocimiento social prioritario en la actualidad. El nuevo perfil de los ciclos vitales femeninos está siendo observado con luces, cámaras y micrófonos.

Los comportamientos masculinos despiertan menos interés. Parecen seguir las pautas de siempre, típicas de sus funciones tradicionales. La «revolución de los géneros» resulta patrimonio de las mujeres, por su progresiva asunción de funciones que, hasta hace poco, 
parecían exclusivas de los hombres. Éstos ya no son los patriarcas que eran, se interesan más por los hijos, pueden tener parejas con más estudios o con posición social y laboral superior, pero nada de eso desdibuja su perfil tradicional de proveedores económicos y «productores» ni los convierte en principalmente «reproductores». Pese a que los varones españoles muestran opiniones muy favorables a la igualdad de responsabilidades con su pareja, sus actos domésticos desmienten sus ideales ${ }^{6}$.

El cambio de los roles de género no tiene, pues, motivo suficiente en las nuevas opiniones, valores o ideologías, ni se limita al marco legal o a la redistribución de recursos por el Estado del Bienestar. Requiere, ineludiblemente, de la eficiencia demográfica inherente a la elevadísima supervivencia actual, y de la consecuente rebaja de las exigencias reproductivas, que es la que hace claramente disfuncional la tradicional asignación de prácticamente la mitad de la población, la femenina, a las tareas de procreación y crianza de los hijos (Garrido, 1996). Para los hombres jóvenes y adultos, por el contrario, los tradicionales roles productivos y de provisión económica siguen siendo funcionales en la propia trayectoria vital y familiar.

\section{¿Y EL RESTO DE EDADES?}

El proceso de igualación, no obstante, tiene lugar en una única dirección, la de acercar a las mujeres a los roles tradicionalmente asumidos por los hombres, si lo observado son sólo los jóvenes. Las edades maduras y avanzadas despiertan poco interés en este asunto, como si en ellas los cambios resultasen ya imposibles. De la visibilidad estadística se pasa a la falta casi total de datos. Lo que les ocurra a los que ya acaban su periodo adulto y alcanzan el ecuador de la vida se conocerá únicamente a través del IMSERSO o de algunas escasas encuestas. Ninguna de tales fuentes tiene como objetivo específico sondear el modo en que cambian los roles de género. De esta manera resulta fácil no encontrar lo que no se busca.

Pues bien, aunque la información disponible sobre quienes ya no son jóvenes ni adultos se haya producido hasta ahora con otros fines, resulta posible reinterpretarla desde el interés por los posibles cambios en las relaciones de género. Bastan para ello ligeros cambios de óptica en el uso que normalmente se le da. No se consigue así equilibrar la

\footnotetext{
6 Según una encuesta sobre los comportamientos de género en los ámbitos privado y público (CIS, 1991), «... la mayoría de la muestra analizada tiene actitudes igualitarias en torno al reparto de las tareas del hogar; sin embargo, esto entra en contradicción con las conductas manifestadas en torno al mismo tema...” (p. 57). Baste un ejemplo: sólo el 18\% de los varones opina que el marido no debería trabajar en las tareas de la casa, y el $79 \%$ considera natural que comparta tales tareas con la mujer (p. 51). En cambio, sólo el 1\% friega los platos, recoge la cocina, hace las camas o limpia la casa (p. 55).
} 
desigual atención prestada a las diferentes edades, pero se evidencia el interés que tendría conseguirlo.

La hipótesis subyacente a la reinterpretación que se propone aquí es que la transición demográfica no sólo ha provocado una nueva distribución por edades, sino que, además, la supervivencia masiva hasta la madurez y a la vejez, así como la eficiencia reproductiva consecuente, tienen repercusiones sobre la significación social del sexo en todas ellas, y no sólo en las más jóvenes. Ya se ha afirmado que, para éstas, ha supuesto un impulso hacia la «masculinización». Se sostendrá a continuación que está impulsando de manera simultánea la «feminización» de las edades posteriores, lo cual puede hacerse desde dos ópticas muy diferentes que serán tratadas por separado:

- por una parte, la madurez de masas está provocando una importante «feminización demográfica» al incrementar considerablemente el peso de las mujeres de edades maduras y avanzadas en el conjunto de la población, y su número respecto al de los hombres de las mismas edades;

- por otra, está remodelando los recorridos vitales para igualar a ambos sexos en tales edades, siendo el modelo hasta ahora exclusivamente femenino el que se muestra mejor adaptado y el que progresivamente asumen los varones.

\section{MÁS MUJERES QUE HOMBRES}

En la España de 1999 hay más mujeres que hombres: son 20.531.518, lo que supone 860.876 personas más que las que presenta el efectivo masculino del mismo año (19.670.642). En otras palabras, por cada 100 mujeres hay 96 hombres.

Sin embargo, nacen más varones. En 1999 hubieron 11.354 nacimientos masculinos más que femeninos ${ }^{7}$, y el mismo fenómeno puede observarse por mucho que retrocedamos en el tiempo o busquemos el ejemplo de otras poblaciones: entre el 51 y el $52 \%$ de los nacimientos son varones. $\mathrm{Si}$, pese a todo, las mujeres son más que los hombres en el conjunto de edades es porque los hombres viven menos.

Las diferencias de mortalidad no son demasiado espectaculares para una misma edad y durante un periodo corto de tiempo, pero sus efectos acumulados en las sucesivas edades

\footnotetext{
7 Tanto los datos de población (Revisión del Padrón Municipal de 1999) como los de nacimientos de 1999 y de años anterio-
} res (Movimiento Natural de la Población) son del INE y pueden consultarse en su página web: http://www.ine.es/inebase/ 
son sorprendentes. La ventaja numérica inicial de los varones se va reduciendo hasta anularse completamente de los 35 a los 40 años. En las edades posteriores la relación ya se invierte: por cada 100 mujeres de 55 a 59 años hay aproximadamente 95 hombres. Y si lo observado son personas de más de 70 años, las diferencias empiezan a ser considerables: a los 85 años hay dos mujeres por cada hombre. Hablar de «los viejos» para referirse a personas de ambos sexos y edad avanzada incurre doblemente en la injusticia de género, porque los viejos no son viejos, sino viejas.

Esta afirmación podría haberse hecho en décadas e incluso en siglos pasados, pero su relevancia sociológica hubiese sido mínima, porque tales edades tenían un peso demográfico muy reducido y escasa participación en la dinámica social. En cambio, precisamente a causa de la elevada supervivencia actual, la preponderancia relativa de las mujeres de edad madura y avanzada se ha convertido en un factor claro de feminización del conjunto social (Pérez Díaz, 2000). Las mujeres de más de 64 años son hoy uno de cada diez ciudadanos españoles ${ }^{8}$.

Este es sólo un primer argumento, aunque de implicaciones cruciales, para sostener la hipótesis de que los cambios demográficos favorecen la feminización de la vejez. Tomado aisladamente puede resultar en exceso estadístico y biologista, y suscitar fundadas reticencias. Las mujeres mayores se acercan demasiado al prototipo que se pretende combatir, la feminización meramente cuantitativa parece una victoria pírrica, y el pensamiento feminista, casi inevitablemente, presta una mayor atención a las mujeres jóvenes (Keller, 1982) que a aquellas cuyas trayectorias están ya muy consolidadas desde épocas en que el progreso social y cultural de España había sufrido un duro golpe (Nash, 1989).

Pero no es necesario que una persona cambie de comportamiento para que cambie su lugar y función en un colectivo. Tanto las mujeres mayores como los hombres jóvenes están viendo sustancialmente modificadas sus posiciones relativas en el conjunto social. Se equivocan quienes encuentran mucho más interesante el cambio entre las jóvenes, porque son ellas las que "se mueven», mientras consideran faltas de interés a las mujeres maduras y ancianas porque es su situación la que se mueve alrededor de ellas. Por el contrario, tiene

\footnotetext{
8 Peso absoluto y relativo de la población, total y femenina, de mayores de 64 años, 1900-2000. INE, Censos y Padrones correspondientes (los datos de 2000 corresponden a la revisión del Padrón Municipal).
}

\begin{tabular}{lrrrrr} 
Año & Población & $>64$ Total & $>64$ Mujeres & $\begin{array}{r}\text { Porcentaje } \\
>64\end{array}$ & $\begin{array}{r}\text { Porcentaje } \\
>64 \text { Mujeres }\end{array}$ \\
\hline 1900 & 18.618 .086 & 968.849 & 508.043 & 5,20 & 2,73 \\
1981 & 37.683 .357 & 4.236 .716 & 2.512 .798 & 11,24 & 6,67 \\
2000 & 40.499 .790 & 6.842 .143 & 3.969 .138 & 16,89 & 9,80
\end{tabular}


pleno sentido preguntarse cómo encajan en la nueva redistribución social de las edades que ha producido la madurez de masas. Urge, de hecho, abordar el estudio de ambos tipos de mujer en pie de igualdad.

\section{LAS CARACTERÍSTICAS DE LA MUJERES DE EDAD MADURA Y AVANZADA}

¿Cuáles son los rasgos sociodemográficos que caracterizan ese modelo de mujer «mayor» tan opuesto al de la «nueva mujer» española? ¿Cómo justifican que se valore tan poco la condición femenina de quienes ya hace tiempo que dejaron de ser jóvenes? Lo que sigue responde a tales preguntas con la descripción y los indicadores sociológicos más extendidos que diferencian ambos sexos en la segunda mitad de la vida y dibujan, de manera aparentemente inexorable, una feminidad madura «negativa» respecto a la juvenil y respecto a la masculinidad de los varones coetáneos. Su posterior examen revelará que todos ellos pueden interpretarse de manera harto diferente.

\section{La supervivencia}

Si la mayor esperanza de vida, sobre todo a partir de las edades adultas, está asociada a los comportamientos femeninos ${ }^{9}$, a los hombres les conviene feminizarse. Dicha conclusión, sin embargo, no es común porque, parece ser, las mujeres pagan más intensamente los estigmas de la vejez y su vida es menos interesante, menos «plena», más insatisfactoria. Añádanse los indicadores sanitarios sobre la mayor morbilidad y la peor percepción de la propia salud entre las mujeres de edad avanzada.

\section{La situación convivencial y residencial}

Una de las consecuencias de su mayor esperanza de vida es que la viudedad es mucho más probable en las mujeres. De hecho, es el estado civil de prácticamente la mitad de las mujeres de más de 64 años, mientras que en los hombres del mismo intervalo de edad supone menos del $20 \%$. Los hombres suelen acabar sus días junto a su cónyuge.

La sobremortalidad de los hombres, sin embargo, no es la única causa de este «mal femenino». Sus efectos se ven multiplicados al combinarse con la hasta ahora tradicional mayor

9 En efecto, existe un consenso generalizado entre los especialistas en que la sobremortalidad masculina es, sobre todo, resultado de las diferencias sociales de comportamiento y de sometimiento a riesgos, más que la consecuencia de diferencias biológicas entre ambos sexos (Carlson, 1990; Retheford, 1975). 
edad de los varones en la pareja, que de por sí bastaría para que la viudedad fuese más frecuente entre las mujeres. Esa diferencia de edad implica, además, que los hijos comunes de una pareja nacen y se emancipan más pronto en la vida de la madre que en la del padre.

Todo parece confabularse para que, desde la madurez, la compañía de familiares directos sea más escasa para las mujeres. La evolución de la estructura de los hogares en España es bastante sintomática: se reduce el número medio de personas en cada hogar y aumenta el peso de los hogares unipersonales, monoparentales y las parejas sin hijos (Requena, 1993). Y no son los jóvenes, sino los de mayor edad, quienes protagonizan principalmente ese cambio. Igualmente disminuyen los hogares en que reside más de un núcleo conyugal y los denominados «extensos», aquellos en que los adultos conviven con sus propios hijos pero también con otros familiares. Tales formas de hogar solían resultar del apoyo familiar a los más ancianos y, aunque minoritarias, han distinguido hasta hace poco a España del resto de Europa, donde ya eran insignificantes. También en nuestro país llevan camino de desaparecer, especialmente para las mujeres, porque sigue siendo mucho más frecuente la convivencia con otros familiares entre los viudos que entre las viudas.

En suma, lo característicamente femenino en las edades avanzadas respecto a la situación convivencial y residencial tampoco parece un modelo a envidiar.

\section{La escasa instrucción femenina}

El escaso papel de la instrucción formal en la vida cotidiana es otra de las características de las mujeres de mayor edad, en consonancia evidente con las funciones familiares que se les asignaron desde niñas. En las generaciones más antiguas, casi el $40 \%$ de las mujeres quedó sin escolarizar, mientras que los hombres no llegan al 30\% (Pérez Díaz, 2001a). Las generaciones posteriores, las escolarizadas durante el franquismo, mejoran su dotación educativa, pero de forma más rápida e intensa entre los varones, lo que aumenta las diferencias entre sexos. Todavía están llegando a los sesenta años generaciones en las que la proporción de no escolarizados es el doble en las mujeres que en los hombres.

La relevancia del nivel de instrucción es harto conocida en sociología. Sus beneficios se constatan claramente en el mercado de trabajo. Su carencia comporta desventajas evidentes en la relación individual con el entorno material y humano y dificulta el acceso a la información y a los servicios. Correlaciona con el nivel de salud e, incluso, con su percepción subjetiva entre quienes tienen un mismo nivel «objetivo» (Puga, 2002). Tampoco en esto parece deseable el prototipo de feminidad que encarnan estas mujeres. 


\section{La situación económica}

Es en las trayectorias laborales y en la situación económica donde se hacen sentir de manera fundamental las consecuencias de la tradicional especialización reproductiva femenina para la «segunda parte de la vida». Determinan las condiciones materiales de vida en el presente.

Las españolas de más edad han tenido una dedicación media al trabajo del hogar que rebasa los cuarenta años, mientras que la dedicación masculina en las mismas generaciones es prácticamente nula. Pero no hay simetría respecto al trabajo extradoméstico. Si son los hombres los que han estado empleados durante más de cuarenta años, los años de empleo femenino, aunque sean menos, no son negligibles. Las mujeres de más de setenta años en la actualidad han estado ocupadas una media próxima a los treinta años (Pérez Díaz, 2001b). Para ello han debido compatibilizar largamente (incluso durante todo el tiempo) el trabajo doméstico y el extradoméstico, cosa que lastra la propia carrera profesional y limita el tipo y categoría de los trabajos accesibles. En muchos casos, la trayectoria laboral no se vio dificultada, sino interrumpida. Tanto si la interrupción fue definitiva como si fue sólo temporal, las consecuencias eran ya irreversibles.

Si el matrimonio hubiese sido realmente una empresa común con funciones repartidas de manera complementaria, tras la jubilación importaría poco quién de los dos fue en su día el proveedor económico. Pero la supuesta complementariedad en lo familiar se ha traducido en realidad en inferioridad económica para estas mujeres. En la propia familia, porque durante décadas se ha restringido su capacidad real e incluso legal de gestión del patrimonio y de los recursos económicos supuestamente comunes ${ }^{10}$. Desde el punto de vista social, porque el derecho a percibir una pensión se ha aplicado con criterios muy diferentes en función del pasado laboral de cada persona y, por tanto, de su sexo.

\section{UNA REINTERPRETACIÓN DE TALES CARACTERÍSTICAS}

No hace falta seguir enumerando. ¿Por qué considerar necesario entonces, urgente incluso, profundizar en el conocimiento de estas mujeres? ¿Qué motivos hay para que sirvan de modelo a los hombres de su misma edad? Todo parece dar por buenas las transformaciones que protagonizan las jóvenes y hacer desventajosa la feminidad que encarnan las mayores. Pues bien, si los datos que abonan esa impresión pueden ser rigurosos, la interpre-

\footnotetext{
10 Hasta tal punto se las relegó a un segundo plano que, en la transmisión del patrimonio de los varones fallecidos, el Código
} Civil amparaba la primacía de los hijos frente a la esposa. 
tación que los acompaña choca con la observación directa. Basta con salir a la calle para comprobar que estas mujeres merecen más admiración que conmiseración, que son ellas las que proporcionan asistencia en vez de recibirla, y que su manera de enfrentar la madurez y la vejez les proporciona ventajas frente a los hombres. Algo falla en la manera típica de presentar sus características.

La principal fuente de malentendidos está en que sus trayectorias vitales se analicen con los patrones aplicables a los varones y con los valores propios de la juventud. La obsesión sociológica por los traumas asociados a la jubilación, por la pérdida de estatus y de funciones sociales y familiares o por la crisis emocional de los cuarenta es sesgadamente andrófila. El empeño en valorar los recursos educativos, relacionales, laborales o económicos en función de su utilidad para los jóvenes y los adultos resulta igualmente inadecuado cuando lo estudiado son personas que ya no tienen tales edades.

Que las mujeres tengan mayor esperanza de vida ya debería ser suficiente motivo de sospecha. Encontrar preferible la masculinidad en este asunto sólo es posible si se estigmatiza la vejez en sí misma. Aun así, las mujeres se enfrentan a ese estigma mucho mejor que los hombres. La mujer de luto permanente por un marido que falleció años ha, en casa de algún hijo considerándose una carga y desplazada por la nuera en sus quehaceres de siempre, que no tiene ahorros ni patrimonio alguno y que no encuentra ningún sentido a la vida que no sea esperar la propia muerte encerrada en casa, personifica un tópico prácticamente extinto.

De las diferencias de instrucción y trayectoria laboral se extraen también conclusiones con excesiva ligereza. Los estudios formales son muy importantes en el igualmente formal mundo del trabajo asalariado, y las diferencias educativas entre sexos resultan intolerables cuando se persigue una competencia justa en ese terreno. Pero suponer que los estudios académicos son la única fuente de conocimientos importantes y útiles en cualquier etapa de la vida conduce, de nuevo, a medir a las mujeres que ya no son jóvenes con el rasero masculino y juvenil. El resultado es el menosprecio de sus particulares conocimientos y habilidades porque no están avalados por una acreditación y no tienen como finalidad el mercado de trabajo. Error nimio para las jóvenes que aspiran a la igualación laboral, pero fatal para los hombres maduros. La vida laboral se acaba, y últimamente con bastante anticipación.

Los varones, educados, formados y aplicados al mundo «exterior» de las relaciones laborales y de las actividades productivas impersonales y contractualmente formalizadas, pierden de repente el suelo bajo sus pies cuando la vida laboral toca a su fin. Sus recursos, conocimientos, habilidades y relaciones no desaparecen, pero se quedan sin lugar de 
aplicación. Nada en su formación les capacita para volver al «mundo real» del hogar, las relaciones informales, las tareas cotidianas de la casa y el mantenimiento de los apoyos familiares. Para sus coetáneas, en cambio, no hay salto ni aterrizaje. Si se dedicaban exclusivamente al trabajo del hogar, no cesa su actividad. Si lo compatibilizaban con una ocupación laboral, la jubilación es mucho mejor recibida. A partir de entonces, se desenvuelven bastante mejor que los hombres.

La jubilación acaba, por tanto, con buena parte de las desventajas que pudiesen derivarse de la menor instrucción femenina, y pone en evidencia, en cambio, la escasez e inadaptación de los conocimientos típicamente masculinos aplicables a la nueva situación.

Incluso un indicador demográfico tan fundamental como las tasas específicas de mortalidad refleja un anormal aumento en las edades finales de la vida activa masculina. A partir de ese momento, la dependencia conyugal se revela descarnada: los hombres, cuando enviudan, tienen una esperanza de vida menor que quienes, a la misma edad, continúan conviviendo con su pareja (Kaprio, Koskenvuo y Rita, 1987). Entre los viudos la incidencia de la depresión es sensiblemente superior que entre los casados o entre las viudas. También lo son la degradación de los hábitos alimentarios, el tabaquismo o el alcoholismo, e incluso la angustia por enfrentar en solitario las tareas domésticas (Lee et al., 2001). La viudedad femenina, mucho más frecuente, no aumenta la mortalidad ni el resto de los anteriores fenómenos (de hecho, el tiempo de dedicación a las tareas domésticas disminuye). No falta quien se deja llevar por el extremismo andrógino y afirma que para muchas de estas mujeres la viudedad es, de hecho, una bendición y no una tragedia. Pero, sin llegar a tales extremos, lo cierto es que, superado el duelo inicial, muchas mujeres adquieren consciencia cabal de su propia individualidad y se abren al mundo con redoblada vitalidad.

En definitiva, estoy sugiriendo que los tradicionales roles femeninos proporcionan a la mujer de edad madura y avanzada una independencia y autosuficiencia que los igualmente tradicionales roles masculinos no han permitido, hasta ahora, a los hombres de las mismas edades.

Esta afirmación topa inevitablemente con las desigualdades económicas. Pero tales condiciones han mejorado sustancialmente en los últimos años, y las generaciones que hoy llegan a la madurez traen consigo aún más cambios. En España más del $82 \%$ de los mayores de 64 años tienen vivienda en propiedad ${ }^{11}$. Están llegando a la vejez las primeras generaciones de nuestra historia que han podido desarrollar su vida laboral y familiar sin que las perturbe una guerra, las primeras cuya juventud fue mayoritariamente urbana, de inserción

11 Datos de la Encuesta de Presupuestos Familiares, 1990-91 (INE). 
laboral asalariada y lejos del sector agrario, las primeras en que la soltería femenina ya no es mayor que la masculina. De matrimonio temprano, con menos hijos que cualquier generación anterior, son las primeras en constituir una familia autónomamente, sin exigir de los hijos su trabajo temprano ni su aportación económica y dándoles, en cambio, estudios medios y superiores. Ahora, a las puertas de la vejez, son ellos y no los jóvenes los que, además de poseer su propia vivienda, disponen de un buen coche, de ahorros en la cuenta corriente e incluso de una segunda residencia.

En tales generaciones el modelo de pareja complementaria ha alcanzado su máxima expresión, y no es la pobreza, sino la especialización en la economía doméstica, lo que diferencia a las mujeres. En sus manos la elasticidad de los recursos familiares resulta sorprendente, y la productividad de su trabajo doméstico es abrumadoramente superior a la de sus cónyuges.

No es de extrañar que, incluso con recursos ciertamente escasos, esté aumentando la independencia de las mujeres mayores. La constatación de esta tendencia puede preocupar a los trabajadores sociales que visitan los hogares más deprimidos, o a los responsables de la política social ante la aparente tendencia a que los hijos se desentiendan de sus padres. Pero tales percepciones están condicionadas por tópicos caducos. Lo cierto es que la creciente independencia domiciliar es un fiel reflejo de la mejora en las condiciones económicas de los mayores.

Añádase la reciente concesión de pensiones no contributivas de vejez (1982), que ha universalizado por fin ese derecho. Aunque no basten para equilibrar las diferencias entre hombres con una vida laboral completa y mujeres amas de casa, el salto de la nada a una pensión mínima es crucial. Por su parte, la pensión de viudedad tampoco proporciona los mismos recursos que una pensión contributiva con cónyuge a cargo, pero la viudedad se ha retrasado considerablemente y la penosa situación de las viudas con hijos todavía por criar es cada vez más rara. Aún más importante es que entre las mujeres de las generaciones que actualmente alcanzan la edad de jubilación la proporción de quienes han tenido trayectorias laborales completas es escasa, pero la proporción de las que fueron alguna vez activas y asalariadas es muy superior a la de las generaciones anteriores (Pérez Díaz, 2001a), de modo que el derecho a la pensión contributiva, aunque no sea completa, se extiende también.

Pese a todo, las precarias mejoras en cuanto a la percepción de pensiones no bastan para explicar la actual independencia de las mujeres mayores. El sistema de pensiones y la protección social pueden haber reducido las desigualdades económicas, pero lejos de hacerlas desaparecer parecen diseñados para perpetuarlas. Lo fundamental es que el cambio 
de la situación económica de quienes superan las edades activas no se debe únicamente, ni siquiera principalmente, a los efectos benéficos del desarrollo del Estado del Bienestar o del sistema de pensiones. El principal motivo de las mejoras es que las generaciones que actualmente llegan a la madurez y a la vejez disponen de más recursos propios que las generaciones más antiguas, y las mujeres se benefician de ello en mayor medida que hace algunas décadas ${ }^{12}$.

Por otra parte, la imagen de soledad y abandono que suele extraerse de las estadísticas sobre estado civil y sobre estructura de los hogares resulta parcial. Tales datos nos hablan únicamente de los convivientes bajo un mismo techo, y nada nos dicen sobre las relaciones reales entre familiares. Es precisamente en el ámbito convivencial y familiar donde más necesario resulta revisar los tópicos sobre la situación respectiva de hombres y mujeres.

La independencia de las mujeres de mayor edad y su papel fundamental en la gestión de sus propios hogares incluso sin grandes recursos (ya sea en pareja o viviendo solas) coinciden con una novedad espectacular: su innegable irrupción como piezas clave en la vida familiar de sus hijos adultos. No se ha valorado suficientemente su papel en la masiva incorporación de sus hijas jóvenes al mercado de trabajo asalariado, pero es una realidad social clamorosa que muchas mujeres trabajadoras cuentan con sus madres para hacer ciertas compras, para «arreglar papeles», para cuidar de los hijos muy pequeños o para traerlos y llevarlos del colegio cuando ya han crecido un poco. Los antecedentes pueden buscarse mucho antes, cuando en plena crisis se lanzaron a la calle a «hacer faenas» ante el paro de sus maridos o, sencillamente, para complementar los ingresos familiares (Garrido, 1992). Estas mujeres contribuyeron a hacer posible para sus hijos la dedicación exclusiva y prolongada a los estudios, dedicación que ha permitido a las jóvenes actuales igualar y superar el nivel de instrucción de los hombres de su misma edad.

Los beneficios no son sólo para los demás: las relaciones son de mutuo interés y no se limitan a las ayudas visibles. Hay en el papel de estas mujeres una función mucho más difusa y difícil de detectar que no se da en los hombres y que las va a beneficiar en sus últimos años: la de mantener la cohesión familiar en un mundo en que los parientes están cada vez más dispersos en hogares diferentes. A la detección de esta función no llegan ni siquiera las encuestas sobre el uso del tiempo, aparentemente pensadas para personas de mediana edad, con horarios divididos entre el trabajo y el ocio. Como ocio califican, precisamente, las visitas, los contactos telefónicos, las pequeñas ayudas domésticas a terceros. Caen

\footnotetext{
12 Al margen de la posible concentración de algunas grandes fortunas familiares en manos de viudas, es mucho más relevante, desde el punto de vista sociológico, que las prácticas de sucesión y herencia estén cambiando de manera generalizada: en su día lo tradicional había sido que heredasen los hijos, con usufructo para el cónyuge; ahora el heredero es el cónyuge y a los hijos simplemente les corresponde la legítima.
} 
así en el mismo saco las horas de visitas «intrascendentes», mucho más frecuentes, y las que conllevan ayudas puntuales pero imprescindibles en casos de urgencia, obviamente excepcionales y escasas en términos absolutos. Unas y otras deberían valorarse de manera diferente en función de la edad. Para que la solidaridad funcione en los casos de urgencia y necesidad, debe existir también una tarea constante de «engrase» de sus mecanismos, como esas horas dedicadas por las abuelas a repasar la vida y milagros de toda la familia que tan banales parecen a algunos, especialmente si son hombres.

Cuando en las más altas instancias de nuestro país se habla del fuerte impacto que puede tener el envejecimiento demográfico sobre los sistemas sanitario y de bienestar social, algunos señalan de pasada que, por suerte, en España la solidaridad familiar tiene un papel muy superior al de las prestaciones del Estado (precisamente la situación a la que querrían llegar muchos otros países desarrollados). El feminismo, ante estas tesis, tiene motivos para desconfiar, porque tras el eufemismo «la familia» se está hablando en realidad de la mujer, y podría ocurrir que se cargasen sobre ella los ahorros que el Estado pueda pretender en el cuidado de los mayores. Lo que nadie parece recordar es que, precisamente gracias a la madurez de masas, la presencia simultánea de cuatro generaciones en una misma familia, en vías de generalizarse, tiene en las generaciones maduras su pivote fundamental. Son ellas, y no las jóvenes, las que cuidan de las personas realmente ancianas. Debería ponderarse, por tanto, la gran rentabilidad de cualquier inversión realizada por el Estado en estas mujeres, en vez de considerarla como un simple gasto.

\section{LA FEMINIZACIÓN DE LOS HOMBRES MADUROS}

Por lo que acaba de verse, aunque las mujeres más jóvenes se acerquen voluntaria o forzosamente a actitudes y funciones hasta hace poco propias de los hombres, cuando se aproxima y traspasa el final de la vida laboral, lo «femenino» sigue siendo perfectamente funcional.

¿Ocurre lo mismo cuando los hombres llegan a la madurez? No es algo que las encuestas parezcan muy interesadas en responder y, de hecho, los datos disponibles resultan bastante escasos. Lo que sí sabemos con seguridad es que las condiciones para mantener los roles masculinos anteriores experimentan un cambio objetivo con la jubilación.

Cuando España era todavía un país eminentemente agrario y la esperanza de vida masculina bastante reducida, los hombres trabajaban mientras las fuerzas se lo permitían, los inactivos eran escasos y la organización interna de las relaciones y de las economías familiares facilitaba el patriarcado sostenido hasta sus últimos años. Ya no. La esperanza de 
vida masculina garantiza muchos años después de la jubilación, ésta se ha adelantado considerablemente y el número de hombres que traspasan la madurez y se convierten en «inactivos» es sencillamente impresionante. Por otra parte, las nuevas condiciones familiares y productivas han acentuado mucho la disfuncionalidad de los roles tradicionalmente masculinos a tales edades, y pocas son las cónyuges o los hijos dispuestos a seguir asumiendo intactas las previas relaciones de poder una vez el «cabeza de familia» empieza a perder los fundamentos objetivos de dicha posición. Quien se empeña en mantenerla pese a todo, se ve obligado a una agria lucha conyugal y familiar durante muchos años, décadas incluso, y a la absoluta inadaptación a su situación real ${ }^{13}$. El ajuste se hace necesario, casi inevitable, y pasa por la asunción de nuevos roles mejor adaptados a esa nueva y duradera etapa de la vida.

No es fácil. Las mujeres jóvenes empiezan a asumir los nuevos roles desde la infancia y de manera gradual, y los antiguos han dejado de parecerles deseables. En cambio, los hombres maduros se ven obligados a una reconversión tardía, mucho más brusca y, en muchos casos, no deseada. Al jubilarse pierden instantáneamente el círculo de relaciones sociales en el que se han movido durante buena parte de su vida. Dejan de estar sujetos a una distribución del tiempo dictada por el trabajo, que regulaba los ciclos cotidianos y las perspectivas para el día siguiente, y deben decidir a qué van a dedicar cada hora del día, qué harán mañana cuando se levanten, o cuáles son sus proyectos para los próximos años. Su formación, habilidades y experiencia laboral, a veces muy amplias y especializadas, dejan de tener ninguna utilidad para la vida que les aguarda. Y cada vez es más frecuente que la jubilación llegue de manera imprevista, por anticipada.

Algún tipo de preparación para la jubilación se está volviendo necesario, y así empiezan a entenderlo las administraciones y algunas empresas (Pérez Díaz, 1996). Sin embargo, lo más corriente es que no haya tal cosa. En la mayoría de los casos, las mejores lecciones de cómo encarar la nueva vida deberán aprenderse en el propio hogar. Para algunos hombres es demasiado, y cuando los varones viven de manera traumática su jubilación las relaciones familiares se resienten y sus mujeres la padecen tanto o más que ellos. Como ya se apuntó anteriormente, incluso la supervivencia puede peligrar.

Desde un punto de vista abstracto, lo que cambia para estos hombres es la significación del tiempo. Para los adultos actuales el tiempo es dinero, pero hasta hace muy poco eso sólo era cierto en los varones. La significación del tiempo ha mostrado siempre diferencias

\footnotetext{
${ }^{13}$ A título de conjetura, quizá sea este uno de los motivos por los que los casos de violencia doméstica que últimamente tanto preocupan a la sociedad española no se limitan a parejas jóvenes. La casuística de tales agresiones en las parejas de más de sesenta años, que tanta perplejidad nos provocan, podría estar relacionada con la pretensión masculina de sostener roles que a cierta edad dejan de tener fundamento objetivo y ya sólo pueden basarse en la imposición.
} 
de género notables en cada una de las etapas de la vida, que se remontan a un pasado muy remoto en el que los varones todavía no eran asalariados, e incluso a tiempos en que el dinero apenas jugaba ningún papel en la realidad cotidiana.

Las primeras etapas de la vida femenina, de manera ancestral y casi universal, han sido mucho más breves que las de los varones. Su principal vía de colocación en la vida, convertirse en «mujer de», apremiaba a las familias para convertir a las niñas en adultas lo más rápidamente posible. Los motivos no eran simplemente culturales, sino que guardaban también relación con otros determinantes mucho más rígidos, como la tradicional escasez de varones casaderos, que recomendaba el matrimonio temprano de las mujeres ante el riesgo de «llegar demasiado tarde». Los hombres tardaban más en convertirse en adultos. Debían esperar a haber aprendido el oficio, a consolidarse económicamente, a heredar las tierras familiares; a ser, en suma, candidatos solventes para formar una familia. $Y$ podían esperar porque el excedente femenino les garantizaba el emparejamiento, aunque fuese tardío. A partir de ese momento, la situación se invertía completamente. El varón adulto se veía inmerso en una vida social altamente formalizada, externa al hogar, con el tiempo regulado socialmente. Para la mujer casada el tiempo se detenía, se volvía blando, interior, autorregulado. Los hombres adultos siempre parecen haber ido en contra del tiempo, con prisas por llegar a cualquier cosa y a cualquier parte, mientras los roles femeninos requerían un tiempo dilatado y una actitud paciente ante las cosas.

La espera forma parte de la feminidad imaginaria en casi todas las culturas. La mujer era la inmóvil, la que aguardaba el regreso de los demás. Esperaba que la «sacasen» a bailar o que el pretendiente «solicitase su mano». Aún hoy los varones se impacientan mientras las mujeres preparan las bolsas para salir el fin de semana, se enojan con el conductor de delante porque va demasiado despacio o encuentran insoportable mirar diez escaparates en vez de comprar en la primera tienda. No es sólo que las sociedades industriales les hayan asignado el papel productivo. En la llíada, las sagas artúricas o las vidas de geishas de la literatura japonesa puede encontrarse esa misma diferencia de género.

Es esa diferencia la que la madurez de masas empieza a resquebrajar. Los hombres maduros están obligados a «feminizar» sus actitudes respecto al uso del tiempo cotidiano, no por imperativos ideológicos o por cambios en sus valores, sino porque la alternativa son muchas décadas de frustración y conflictos. Si bajamos de las consideraciones abstractas al terreno más palpable de los comportamientos cotidianos, los signos del cambio en los hombres jubilados son abundantes. Empiezan a integrar la espera y la paciencia en actividades cotidianas como hacer la compra o ir a buscar los nietos al colegio. De hecho, los nietos pueden llegar a convertirse en uno de los asideros importantes ante la nueva situa- 
ción ${ }^{14}$. Muchos hombres jubilados tienen la sensación de haber perdido la oportunidad de intervenir realmente en la crianza de sus propios hijos porque, cuando los tuvieron, su rol masculino encaminaba su tiempo, sus recursos y sus intereses en otra dirección. Con los nietos tienen una segunda oportunidad y, a menudo, cumplen los requisitos que les faltaron en la primera. En tales casos establecen relaciones emocionales que no son equivalentes a las de las abuelas, todavía apegadas a los asuntos cotidianos más imperativos y materiales.

Nuestras fuentes estadísticas no están diseñadas para captar cambios como estos en los varones ni para evidenciar el papel activo fundamental de los mayores en general en apoyo a sus hijos. Una encuesta específica sobre la reciprocidad familiar de estas personas (INSERSO, 1995), que podría haber aportado información valiosa al respecto, se contenta con constatar que un 35\% de los mayores de 64 años y que tienen descendencia ayuda a sus hijos, y que la ayuda tiene un carácter regular, no esporádico, cuando las hijas son madres y trabajan. Ese porcentaje oculta datos aún más espectaculares por culpa del instituido hábito de tratar en un único grupo a los mayores de 64 años. Como la mayoría de tales mayores «ayudantes» deben concentrarse en las edades más jóvenes de la vejez, en tales edades la proporción debe ser muy superior, y es probable que aún lo sea más entre quienes tienen de 50 a 64 años, aunque no aparezcan en la encuesta. También los resultados directos sobre la distribución de tales ayudas en función del sexo resultan significativos. Constatan que las ayudas en forma de trabajo doméstico son más frecuentes por parte de las madres que de los padres (53\% vs. $23 \%$ ), y lo mismo pasa con la compra ( $29 \%$ vs. $20 \%$ ) (p. 79 ), con lo que se confirma algo ya sabido y, en cambio, se pasa por encima de unos porcentajes masculinos completamente inusitados que rompen todos los tópicos.

En general, al margen de las tareas del hogar, en las que sus incursiones empiezan a ser visibles, la función tradicional femenina que mejor pueden asumir los hombres maduros es el cuidado de otros familiares. El de los niños es sólo una de sus versiones, pero hay muchas otras que también están dejando de ser una excepción.

El cuidado de los enfermos es tan tradicionalmente femenino como la crianza de los niños. Incluso en los centros sanitarios, los hombres intervienen examinando, diagnosticando, prescribiendo tratamientos... y acto seguido desaparecen. El seguimiento, el suministro de los fármacos, la observación continuada, el apoyo emocional, siguen siendo mayoritariamente femeninos. No es una función intensiva, sino extensiva en tiempo; es acción sin ac-

\footnotetext{
14 En los mayores que ayudan regularmente a los hijos con familia propia es más frecuente el cuidado de los nietos entre los
} hombres (75\%) que entre las mujeres (66\%) (INSERSO, 1995, p. 79). 
ción, estar sin hacer, “compartir el tiempo con...», roles que los hombres pueden asumir fácilmente una vez jubilados. De hecho, cuando lo hacen, demuestran que la supuesta incompetencia masculina para tales tareas es un mito (Miller y Cafasso, 1992).

Con la evolución actual de la supervivencia, los receptores de cuidados informales que más van a crecer son las personas muy ancianas con dependencias funcionales importantes. Hasta ahora el perfil típico de sus cuidadores en España podía definirse como de «género femenino, número singular» (Rodríguez, 1999). Pero las jóvenes ya no son cuidadoras de ancianos. Sería vano buscar explicaciones morales, apelar a la degradación de los valores familiares tradicionales o a cualquier otro factor cultural, cuando es la inexorable «masculinización laboral» de las mujeres jóvenes la que elimina del panorama una proporción considerable de potenciales cuidadores. Son las personas maduras o en su primera vejez quienes hoy asumen tales responsabilidades. Por ello, la madurez de masas debería ser una buena noticia: las edades potencialmente cuidadoras están experimentando un aumento numérico mucho más rápido que las edades anteriores. Paradójicamente, cuando se hacen proyecciones de posibles cuidadores no se incluye a los varones ${ }^{15}$.

En otros países donde ya hace tiempo que los hombres maduros constituyen una parte considerable de la población, su papel de cuidadores es tan importante como el de las mujeres de su misma edad (Arbert y Gilbert, 1989). En Estados Unidos, por ejemplo, la relación entre hombres y mujeres cuidadores es de 4 a 5 (Chang y White-Means, 1991). Puesto que en las edades maduras hay más mujeres que hombres, una relación de 4 a 5 supone prácticamente que ambos sexos están ejerciendo funciones cuidadoras con intensidad similar. De hecho, Chang y White-Means sostienen también que los hombres son perfectamente competentes para ello, sobre la base de diversas investigaciones de las que se deduce incluso que su predisposición anímica es mejor que la de las mujeres.

El pesimismo, pese a todo, consigue transmitirse a la opinión pública. Nuestros mayores siguen prefiriendo, si llegan a necesitar cuidados especiales por alguna discapacidad, que se los dispensen en su propio hogar, y que los cuidadores sean sus propios hijos (INSERSO, 1995, p. 83). Los adultos también creen que tales deben ser las condiciones en que se cuide de los ancianos. Sin embargo, también son mayoría los mayores convencidos de que no será así, porque las mujeres cada vez trabajan más y porque se está perdiendo el sentido de la obligación hacia los padres. Sólo lo primero es cierto. Nadie parece contar con la

\footnotetext{
15 A título de ejemplo, la previsión que de la relación entre cuidadores potenciales y potenciales ancianos dependientes hace uno de nuestros mejores demógrafos (Fernández Cordón, 1992), basándose en las proyecciones de población por sexo y edad. El indicador clave es la relación entre las mujeres de 45 a 69 años y los mayores de 64 , con lo que se niega, por principio, ningún papel cuidador a los hombres. Y así, si en 1950 había 1,61, en el 2011 la relación será ya inversa, y habrá menos de un cuidador potencial $(0,96)$ por cada mayor de 64 años. Es el indicador habitual en este tipo de estimaciones, pero resulta obviamente opaco a los posibles cambios de roles en la madurez.
} 
madurez de masas ni tener en cuenta la redefinición de roles que se está operando entre diferentes edades tanto en un sexo como en el otro.

\section{CONCLUSIONES}

Se puede banalizar la hipótesis principal aquí sostenida: los hombres de más de sesenta años no han empezado a ponerse faldas. Pero, desde el punto de vista demográfico, estamos asistiendo a la aparición de un colectivo masculino sin precedentes que no tiene por función social prácticamente nada de lo que hasta ahora parecía caracterizar la masculinidad. Aún más, las funciones de ambos sexos y de todas las edades se están redistribuyendo según un patrón muy diferente al que existía hasta ahora. La tendencia podría conducir a una nueva distribución de roles cuya expresión sintética se muestra en el gráfico adjunto. Su intención es meramente especulativa, pero existen importantes factores objetivos impulsando una reestructuración como esta, y hacen falta enfoques de investigación diferentes a los seguidos hasta ahora si se quiere comprender el impacto de la transición de la mortalidad y de la fecundidad en la estructura social. Hasta ahora, la nueva estructura por edades ha sido analizada manteniendo fijos todos los demás comportamientos, especialmente los asociados al sexo y la edad.

Esquema ideal del posible cambio en la distribución de roles por sexo y edad

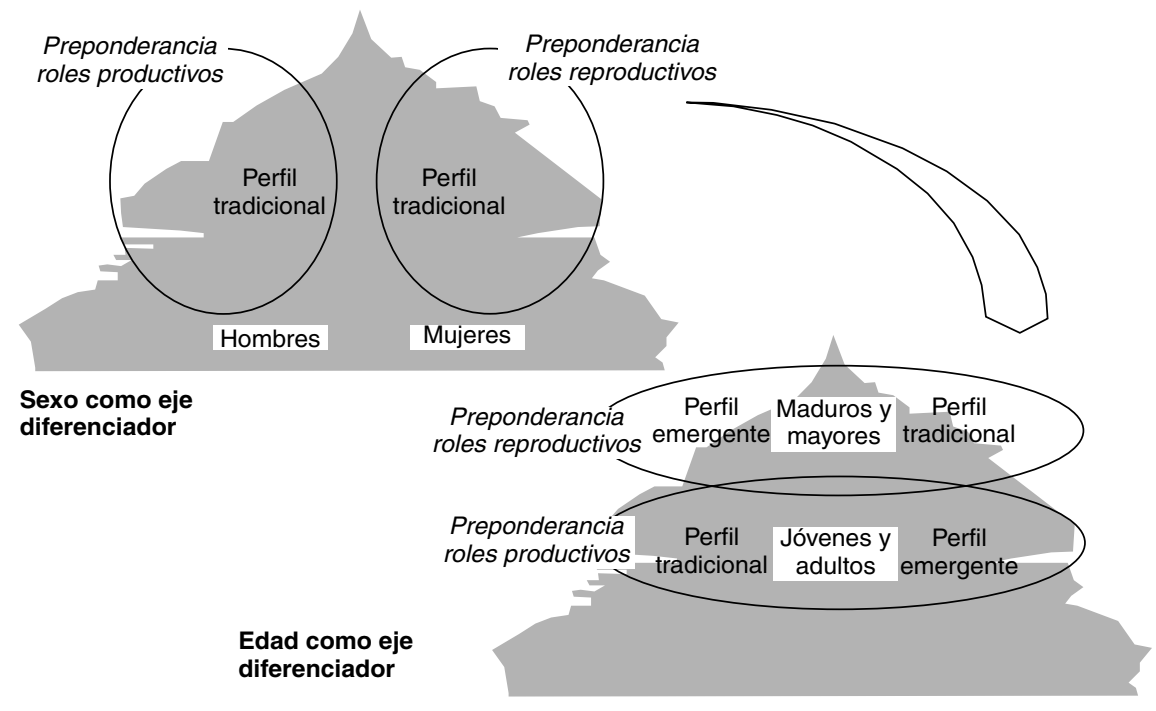

NотA: Se utiliza la expresión «roles reproductivos» en un sentido amplio, no limitado a la mera reproducción biológica. 
Lo que sugiere el esquema es que, por el contrario, los cambios en la supervivencia, la reproducción y la estructura por edades han ido acompañados de una redistribución de las funciones productivas y reproductivas. Por ello no concuerda con la extendida idea de que las funciones de «reproducción social» disminuyen en frecuencia e intensidad, sino que sugiere que están experimentando un desplazamiento entre edades y sexos. Puede ser impulsado o combatido, según se valore, y ya se comentó en la introducción la creciente capacidad de asignación de recursos y de posiciones sociales que tiene actualmente el Estado. Sus acciones respecto al apoyo a las familias, a las madres trabajadoras, al cuidado de los dependientes o al importe y extensión de las pensiones afectarán a la futura distribución de roles. Pero conviene saber que existen tendencias sociales con una alto grado de inercia y un largo tiempo de desarrollo, que desafían las políticas puntuales y la planificación estatal.

El descenso de los requerimientos de reproducción biológica es una de tales tendencias, pero también lo es el aumento de los que tienen que ver con la reproducción social y con la satisfacción emocional. Se tienen menos hijos, pero se invierte en ellos mucho más (Becker, 1981). Las parejas pueden ser más «libres», pero responden a una exigencia de satisfacción personal y afectiva nunca vista (Domingo, 1997; Beck y Beck, 1998). Lejos de «la muerte de la familia» anunciada por Cooper (1972), se generaliza e intensifica el apoyo intergeneracional en las líneas de filiación, tanto en sentido ascendente como en el descendente. Simplemente, las mujeres jóvenes y adultas han dejado de ser las únicas «encargadas» de todos los servicios, trabajos y atenciones que requiere la «función reproductiva». Considerar que ello se debe únicamente al aumento de su actividad laboral es simplista en grado sumo (Oppenheimer, 1994). La causalidad puede predicarse en sentido inverso: ha sido la descarga de funciones reproductivas la que ha hecho posible ese cambio, y aquí se sugiere que en dicha descarga el creciente papel «reproductivo» asumido por los mayores ha sido fundamental.

En suma, la progresiva desvinculación de la reproducción social del sexo y de las edades fértiles, a la vez que la elevación inusitada de sus requerimientos económicos y emocionales, permite e impulsa estrategias sociales de reproducción diferentes a las tradicionales. Se ha investigado mucho el papel del Estado del Bienestar o del crecimiento del mercado de bienes y servicios en dicho cambio, aceptando el supuesto de que el desarrollo no ha hecho más que vaciar de funciones a la familia. Esa interrelación entre Estado y mercado es la que guía la trascendental obra de Esping-Andersen (1993) que sitúa la economía política en el centro del análisis de la estructura social. Como se le ha criticado y el propio autor asume en trabajos posteriores, su famosa clasificación de los distintos tipos de Estados del Bienestar en función del grado de desmercantilización de las personas presta poca atención a la concurrencia de la familia con el Estado como instancia capaz de proporcio- 
nar recursos y servicios al margen del mercado. En consecuencia, países como los mediterráneos acaban siendo clasificados de manera poco satisfactoria. En mi opinión, es en tales países donde la feminización de la vejez puede resultar más importante, y también más difícil y traumática.

España es un buen ejemplo de la escasa intensidad desmercantilizadora de un Estado del Bienestar poco pródigo, que delega en la familia funciones novedosas, surgidas a medida que el país va igualándose al resto de Europa en riqueza y desarrollo. El Estado aprovecha así estrategias tradicionales de solidaridad familiar todavía vigentes a causa del retraso con que el país ha culminado su modernización. Han sido los padres los que han costeado las consecuencias del elevadísimo paro juvenil generado por las dos grandes crisis de empleo del último cuarto de siglo. Han cargado también con la mayor parte del gasto que ha permitido a los jóvenes, y sobre todo las jóvenes, ampliar estudios hasta extremos nunca vistos ante el cierre del mercado laboral. No es de extrañar que la emancipación juvenil y la nupcialidad sean en España de las más tardías y escasas de Europa (Miret, 1997). Las personas muy ancianas y con graves problemas de dependencia cuentan en España con un claro déficit de plazas residenciales y de asistencia pública, y de nuevo es el cuidado «informal» de sus hijos e hijas, ya maduros o en su primera vejez, el que resuelve la papeleta $(\mathrm{CIS}, 2000)^{16}$.

Se da así la paradoja de que la fecundidad más baja del mundo se dé en un país donde la familia sigue siendo muy importante, donde aún resulta escasa la proporción de las «nuevas formas de hogar» que caracterizan la tan europea «segunda transición demográfica» (Van de Kaa, 1987) (mientras que los hogares nucleares mantienen una preponderancia notable) y donde la actividad femenina, aunque creciente, sigue siendo muy inferior a la del conjunto europeo.

Esta paradoja no ha pasado desapercibida para los muchos analistas conscientes de que la fecundidad de países como España o Italia requiere una explicación urgente. De manera harto contradictoria, se ha querido encontrar tal explicación en el carácter tradicional de sus familias (Tapinos, 1999), e incluso en la pervivencia del patriarcado y del machismo (McDonald, 2000), que disuadirían a las mujeres jóvenes de pasar de lo público, igualitario, a lo privado, complementario. Ninguna de las explicaciones hace honor a la extraordinaria transformación experimentada por la familia en tales países.

Sugiero que la sobrecarga de funciones, que ha convertido a la familia en una formidable agencia de bienestar y protección con escasos apoyos públicos, es la que disuade a los jó-

16 Y, a este paso, incluso con el de los cuidados formales: recientemente se ha determinado en Cataluña que los hijos tienen la obligación legal de correr con parte del coste de las plazas residenciales públicas si los recursos del anciano son insuficientes. 
venes de constituir tan costosa empresa y les permite, al mismo tiempo, vivir de sus padres indefinidamente. Puede que la política de apoyo a las familias quedase tan desprestigiada en España tras el franquismo que los posteriores gobiernos democráticos huyesen de ella. Lo cierto es que el Estado lleva décadas dejando la reproducción social, cada vez más costosa, en manos de la familia sin incrementar su apoyo (Iglesias y Meil, 2001), con dos resultados aparentemente contradictorios: las familias ya existentes se han vuelto cada vez más importantes y necesarias para sus miembros, y las familias de nueva creación son cada vez más escasas, se constituyen más tarde, y sus descendencias son menores.

Se trata de una dinámica que se autoalimenta. Cuanto más se carga a la familia de responsabilidades, menos posibilidades tienen los jóvenes de constituir la suya propia, durante más tiempo siguen dependiendo de la familia y más responsabilidades sigue acumulando ésta. Tal situación sólo es posible gracias a la supervivencia masiva de los adultos maduros y mayores, a su pertenencia a generaciones con unos recorridos vitales «tradicionales» y a su gran flexibilidad (nada tradicional) ante la nueva situación. En tales condiciones, la feminización de la vejez y el nuevo reparto de roles productivos y reproductivos en función de la edad podrían estarse precipitando en España y, en general, en los países mediterráneos.

Estoy con quienes piensan que una proporción creciente de personas sin descendencia puede convertirse en un problema social, pero no por motivos de política demográfica, sino porque rompe la cadena de solidaridad intergeneracional dentro de las líneas de filiación vertical, cada vez más importantes para el bienestar de las personas a todas las edades. En vez de luchar contra la igualación de los sexos en las edades jóvenes, y fomentar contra corriente una mayor dedicación de las jóvenes a sus tareas tradicionalmente femeninas, convendría reconocer el potencial de las personas de mayor edad, incluidos los varones (especialmente ellos), para desempeñar papeles importantes en la sostenibilidad de los hogares de sus hijos jóvenes y adultos. Ya han empezado a hacerlo, y la tendencia se acentuará en el futuro, pero se trata de una revolución silenciosa, poco investigada, y aún menos apoyada. Quizá suene descabellado, pero la mejora de las prestaciones a las personas maduras o a las que están en la primera vejez podría repercutir en mayores facilidades para que sus hijos formen su propia familia y tengan más hijos. Las ventajas no acabarían ahí, porque también la otra gran preocupación resultante de la evolución demográfica, la del aumento de la dependencia senil, encontraría una respuesta positiva.

Por la primacía que los españoles otorgan a la familia en la vejez, resulta evidente que la dependencia familiar no se ha convertido en una función del pasado, finalmente trasladada al Estado. En otros países europeos, como Francia, Alemania o Gran Bretaña, donde la intervención de las instituciones sanitarias y protectoras estaba más desarrollada, hace años que se pretende la reorientación de esos gastos, especialmente los derivados de las pla- 
zas públicas en residencias de ancianos, hacia otras formas de cuidado. Las más convenientes parecen la asistencia a domicilio y el fomento del apoyo familiar, porque impiden el aislamiento del entorno social y mejoran la calidad de las condiciones anímicas y emocionales. En vista de ello, resulta urgente plantearse si el protagonismo de la familia española en la asistencia a los mayores indica que nuestro sistema de bienestar lleva retraso en la senda ya transitada por otros países europeos, o si más bien ha tomado un atajo hacia la situación futura que éstos pretenden.

La respuesta a esta pregunta va a tener repercusiones importantes. Lo que se plantean esos otros países es una nueva "orientación del gasto», no su eliminación, mientras que en nuestro país parecen existir tentaciones de lo contrario, a costa de las familias. Las consecuencias podrían ser graves, porque la dependencia somete a los cuidadores a presiones considerables, y los maduros podrían ver sobrecargadas sus responsabilidades si, paralelamente, no se les apoya en esa tarea. Corremos simultáneamente varios riesgos: perder la oportunidad histórica de que el final de la vida laboral sea realmente una etapa de libertad comparativa; degradar la calidad e intensidad de la atención a nuestros dependientes; bloquear la necesaria y predecible inversión de roles entre los hombres que alcanzan la madurez. En tales condiciones, España no habría tomado ningún atajo. Esa situación, se mire como se mire, sería un atraso.

\section{BIBLIOGRAFÍA}

ALBERDI, I. (ed.) (1995): Informe sobre la situación de la familia en España, Madrid, Ministerio de Asuntos Sociales.

ALBERDI, I., y ESCARIO, P. (1986): Estudio sociológico sobre las viudas en España, Madrid, Ministerio de Trabajo y Seguridad Social.

ARBE y GIN (eds.) (1995): Connecting Gender and Ageing: a sociological approach, Buckingham and Philadelphia, Open University Press.

ARBER, S., y GILBERT, N. (1989): «Men: the forgotten carers», publicado en Sociology, 23 (1).

BEAUVOIR, S. de (1983): La vejez, Barcelona, Edhasa.

BECK, U., y BECK-GERNSHEIM, E. (1998): El normal caos del amor, Barcelona, EI Roure.

BECKER, G. (1981): A Treatise on the Family, Cambridge, Harvard University Press.

BELL, M. J. (1986): Women as Elders. The Feminist Politics of Aging, New York-London, Harrington Park Press.

CABRÉ I PLA, A. (1994): «Tensiones inminentes en los mercados matrimoniales», incluido en Jordi Nadal, El mundo que viene, Madrid, Alianza Editorial.

CALDWELL, J. C. (1983): «Direct Economic Costs and Benefits of Children», en R. A. Bulatao y R. D. Lee, Determinants of Fertility in Developing Countries, New York, Academic Press, vol. 1. 
CARLSON, E. (1990): «European contrasts in sex ratios: implications for living arrangements in old age», publicado en European Journal of Population, 6 (2): 117-141.

CENTRE D'ESTUDIS DEMOGRÀFICS (2000): Demografía: una cuestión de dos sexos y cuatro generaciones, Informe para la Dirección General V (Empleo, Relaciones Industriales y Asuntos Sociales) de la Comisión Europea (SOC 98 101297-05E01).

CHANG, C. F., y WHITE-MEANS, S. I. (1991): «The men who care: An analysis of male primary caregivers sho care for frail elderly at home», publicado en Journal of Applied Gerontology, 10: 343-358.

CIS (1991): Las mujeres españolas: lo privado y lo público, Madrid, Estudios y Encuestas, n. ${ }^{\circ} 24$.

- (2000): Apoyo informal a las personas mayores y el papel de la mujer cuidadora, Madrid, Opiniones y Actitudes, n. ${ }^{\circ} 31$.

COOPER, D. (1972): The Death of the Family, Harmondsworth, Penguin Books.

CUMMING, E., y HENRY, E. (1961): Growing old, the process of disengagement, New York, Basic Books.

DÍAZ CASANOVA, M. (1989): «Envejecimiento de la población y conflicto entre generaciones», publicado en Revista Española de Investigaciones Sociológicas, 45: 85-113.

DOMINGO I VALLS, A. (1997): La formación de la pareja en tiempos de crisis. Madrid y Barcelona, 1975-1991, Tesis Doctoral, UNED, Facultad de Ciencias Políticas y Sociología.

DONZELOT, J. (1979): La policía de las familias, Valencia, Pre-Textos.

ESPING-ANDERSEN, G. (1993): Los tres mundos del estado del bienestar, Valencia, Edicions Alfons el Magnànim.

FERNÁNDEZ CORDÓN, J. A. (1992): Les personnes agées en Europe: Rapport national, Espagne, Bruselas.

GARRIDO MEDINA, L. (1992): Las dos biografías de la mujer en España, Madrid, Instituto de la Mujer, Ministerio de Asuntos Sociales.

- (1996): «La revolución reproductiva», incluido en C. Castaño y S. Palacios, Salud, dinero y amor. Cómo viven las mujeres españolas de hoy, Madrid, Alianza, pp. 205-238.

GÓMEZ REDONDO, R. (1992): La mortalidad infantil española en el siglo xx, Madrid, CIS-Siglo XXI.

HAREVEN, T. K. (1994): «Aging and Generational Relations: A Historical and Life Course Perspective», publicado en Annual Review of Sociology, 20: 437-461.

IGLESIAS, J., y MEIL, G. (2001): La política familiar en España, Barcelona, Ariel.

INSERSO (1995): Las personas mayores en España. Perfiles. Reciprocidad familiar, Madrid, Ministerio de Asuntos Sociales.

KAPRIO, J.; KOSKENVUO, M., y RITA, H. (1987): «Mortality after bereavement: A prospective study of 95.647 widowed persons», en American Journal of Public Health, 77: 283-287.

KELLER, M. (1982): «Les femmes âgées: les oubliées du féminisme», incluido en Pierre Gilliand, Vieillir aujourd'hui et demain, Lausanne, Réalités Sociales, pp. 463-480.

LEE, G. R.; DeMARIS, A.; BAVIN, S., y SULLIVAN, R. (2001): "Gender Differences in the Depressive Effect of Widowhood in Later Life», publicado en Journal of Gerontology: Social Sciences, 56B (1): s56-s61.

LIVI BACCI, M. (1990): Historia mínima de la población mundial, Barcelona, Ariel. 
LONGMAN, P. (1987): Born to Pay: The New Politics of Aging in America, Boston, Houghton Mifflin Company.

MARKSON, E. W. (1993): «Las ancianas en Estados Unidos: mitos y realidades», publicado en Papers, Revista de sociología, 40: 137-152.

McDONALD, P. (2000): «Gender equity, social institutions and the future of fertility», publicado en Journal of Population Research, 17 (1): 1-16.

MILLER, B., y CAFASSO, L. (1992): «Gender differences in caregiving: fact or artifact?», publicado en Gerontologist, 32: 498-507.

MORENO, L. (2001): “'Supermujeres” y bienestar en las sociedades mediterráneas», publicado en Claves de Razón Práctica, abril (111): 49-53.

NASH, M. (1989): Las mujeres en la Guerra Civil, Madrid, Ministerio de Cultura.

OPPENHEIMER, V. K. (1994): «Women's rising employment and the future of the family in industrial societies», publicado en Population and Development Review, 20 (2): 293-342.

PARSONS, T. (1942): «Age and sex in the social structure of the United States», publicado en American Sociological Review, 7: 604-616

PARSONS, T.; SHILS, E., et al. (1951): Towards a General Theory of Action, Cambridge, Mass., Harvard University Press.

PÉREZ DÍAZ, J. (1995): «Las mujeres ancianas, la auténtica vejez de la España actual», en Papers de Demografia, 99 (Centre d'Estudis Demogràfics).

- (1996): «Jubilació i vida activa», incluido en Generalitat de Catalunya, Pla de preparació per a la jubilació activa, Barcelona, Dep. de Benestar Social, pp. 35 y ss.

- (2000): «La feminización de la vejez», en Papers de Demografia, 182 (Centre d’Estudis Demogràfics).

- (2001a): Transformaciones sociodemográficas en los recorridos hacia la madurez. Las generaciones españolas 1906-1945, Tesis Doctoral, UNED, Facultad de Ciencias Políticas y Sociología, Madrid.

- (2001b): «¿Cómo ha mejorado tanto la vejez en España?», en V. Montes y C. Gomes, Envejecimiento demográfico y políticas públicas para Adultos Mayores. México en Iberoamérica ante el nuevo siglo, Colección «México, los escenarios del nuevo siglo».

- (en prensa): El advenimiento de la madurez de masas, Barcelona, Servei d'Estudis de la Caixa.

PRESTON, S. H. (1984): «Children and the Elderly: Divergent Paths for America's Dependents», publicado en Demography, 21 (4): 435-457.

PUGA GONZÁLEZ, M. D. (2002): Dependencia y necesidades asistenciales de los mayores en España, una previsión a 2010, Madrid, Fundación Pfizer.

QUADAGNO, J., y REID, J. (1997): «The Political Economy Perspective in Aging», publicado en Pepper Institute on Aging and Public Policy, Working Papers 46.

RAMIRO FARINAS, D. (1998): La evolución de la mortalidad en la infancia en la España interior, 1785-1960, Tesis Doctoral.

REQUENA, M. (1992): “Secularización, clases de edad y generaciones; el caso de la sociedad española», incluido en C. Moya, A. Pérez Argote, J. Salcedo y J. F. Tezanos, Escritos de teoría sociológica, Madrid, CIS, pp. 9931018. 
REQUENA, M. (1993): «Formas de familia en la España contemporánea», incluido en L. Garrido Medina y E. Gil Calvo, Estrategias familiares, Madrid, Alianza Editorial, pp. 249-270.

RETHEFORD, R. D. (1975): The changing sex differtential in mortality, Wesport-London, Greenwood Press.

RODRÍGUEZ RODRÍGUEZ, P. (1999): «El problema de la dependencia en las personas mayores», incluido en Ricardo Moragas, El reto de la dependencia al envejecer, Barcelona, Herder.

SANZ GIMENO, A. (1999): La mortalidad de la infancia en Madrid. Cambios demográficos en los siglos XIX y XX, Madrid, Consejería de Sanidad y Servicios Sociales, Comunidad de Madrid, Documento Técnico de Salud Pública, n. ${ }^{\circ} 57$.

SEGALEN, M. (1995): «Continuités et discontinuités familiales: approche socio-historique du lien intergénérationnel», incluido en Claudine Attias-Donfut, Les solidarités entre générations. Vieillesse, familles, état, France, Editions Nathan, pp. 27-40.

SOROKIN, P. (1941): Social and Cultural Dynamics, New York, American Books.

TAPINOS, G. (1999): “L'Europa mediterrània i els canvis demogràfics. Hi ha una especificitat pròpia dels països del sud?», incluido en M. A. Roque, L'espai mediterrani llatí, Barcelona, Institut Català de la Mediterrània, pp. 111-138.

VAN DE KAA, D. J. (1987): «Europe's Second Demographic Transition», publicado en Population Bulletin, 42 (1) (Washington, DC: Population Reference Bureau).

WALKER, A. (1991): «Thatcherism and new politics of old age», incluido en J. Myles y J. Quadagno, States labour market and the future of old age policy, Nueva York, Nueva York Temple University Press.

This article upholds the view that the transformation of population dynamics known as «demographic transition» is an important motor for change not only in the distribution of the population between the various age groups, but also in that of the roles tradicionally assigned to each sex.

It is a question of closely related changes. The growing weight of people of mature and advanced years and the generalization of survival to those ages open up new possibilities for social and family organization, and new individual life-cycle «designs». I shall support the view that the distribution of productive and reproductive roles is ceasing to move around sex, and is becoming articulated around age. It is a well-known fact that the youth and adult age groups are increasingly turning towards types of conduct hitherto considered to be «masculine», and it is suggested that those in the mature and advanced years age groups could be experiencing an inverse preponderance of those others considered hitherto as «feminine». It is this phenomenon of the «feminization of old age» which I aim to demonstrate here, arguing, besides this, the social advantages and risks that it involves. 